\title{
An NCAA Football Bowl Subdivision Production Function
}

\author{
Stacey L. Brook \\ Driehaus College of Business \\ DePaul University
}

\begin{abstract}
:
Each year pundits across the NCAA football landscape debate the validity of various NCAA football teams' relative worthiness to play for the national championship. Given this debate seems to revolve around which team is the best in terms of total team production, I have developed and statistically estimated a complex invasion NCAA football bowl subdivision production function measuring NCAA football team productivity covering the 2008 to 2017 seasons. The model estimates both points scored and points surrendered for each team during this time period and then is combined to determine each team's overall productivity. Finally, as an application of the complex invasion college football production function model, I have ranked the overall productivity of the NCAA football bowl subdivision teams for the 2017 season to find the most productive team. The model concludes that the University of Alabama was the most productive team for the 2017 season.
\end{abstract}

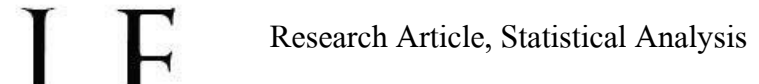

Journal of Emerging Sport Studies

$\iint \begin{aligned} & \text { Volume 1, (2018): London, Ontario } \\ & \text { All Rights Reserved, 2018: ISSN - 2562-3184 }\end{aligned}$
} 
As surely as we can count on autumn leaves changing the color of many US landscapes, we can count on a debate across the NCAA college football landscape as to who is the best team in the NCAA Football Bowl Subdivision (FBS). Coaches, players, athletic directors, members of the media, boosters and fans each have their own criteria as to why one team is better than another. Yet a potential problem in evaluating team performance revolves around the consistency and accuracy of the criteria used in the evaluation process.

To overcome this potential problem, I propose using a statistical model of team performance that weights the individual actions of each team equally to yield a consistent measure of team performance. Thus, for each variable (on-field action), the difference in overall productivity is determined around the quantity that occurs on the field. For example, if team A has 100 units of variable $\mathrm{X}$ and team B has 50 units of variable X, then, with respect to variable $\mathrm{X}$, team $\mathrm{A}$ is twice as productive as team $\mathrm{B}$.

In terms of accuracy, the statistical model allows one to measure each variable in terms of a single unit (in the model that follows I measure them in terms of the impact the variable has on points scored or points surrendered). Thus, different independent variables are now weighted in terms of the same dependent variable. Some actions (variable X) are more important that others (variable Y) and the statistical model allows one to determine the various weights of each variable. Additionally, some variables do not have any statistical effect (i.e. variable $\mathrm{Z}$ is statistically insignificant) and the model can also provide evidence to support this.

Thus, a sports production function allows one to create a consistent and accurate way of measuring each team's productivity. Here I will use a sports production model of NCAA FBS to determine the overall productivity of each team using a complex invasion production model (Gerrard, 2007) described below. The focus of this paper is to present the two stages of the complex invasion sports model of NCAA FBS team performance and provide a NCAA FBS production function where output (measured by the team's points scored and points surrendered) is a function of inputs (team on-field performance).

\section{Literature Review}

There have been numerous empirical estimations of ranking college football teams. For example, Coleman (2005) creates a model to minimize game score violations, which is updated by Miles, Fowks and Coulder (2010), and iterative models, such as Wigness, Williams and Rowell (2010), are used to rank college football teams. Closer to the model presented below, linear models, such as West and Madhur (2008) and Gill and Keating (2009), are used to create and assess rankings of college football teams.

While economic estimations of production functions have been around for a long time, within the last few decades there has been a resurgence of applying the economic idea of a production function to team sports. For example, Fair \& Oster (2007) estimate optimal weights for rankings systems and conclude that the college football betting market is efficient and Beard \& Caudill (2009) use pairwise comparisons to rank college football teams. Gerrard (2007) provides a general hierarchical structural model of a sports production function for complex invasion sports in which the team's overall success is a function of the team's ability to score points and the team's ability to reduce their opponent from scoring points. A team's point scoring productivity is a function of the players' ability to perform actions that significantly affect team scoring and minimize actions that significantly reduce team scoring. Likewise, a team's opponent's point scoring productivity is a function of the players' ability to perform actions that significantly reduce their opponent from scoring and to minimize actions that significantly increase their opponent's scoring.

This complex invasion sports production model, which has only recently been formalized in the literature, has conceptually been used on numerous occasions in sports team productivity literature. The first sports team production functions were for Major League Baseball, starting with Scully (1974), where Scully models team performance (winning percentage) based on two variables: team slugging average and team strike-out to walk ratio. Blass (1992) has updated the production function model to better estimate an individual player's marginal product, by using a runs-scored model and then estimating the impact of the player's contribution on the team's contribution. Subsequently, sports team production functions were extended to the National Basketball Association, such as by Berri $(1999,2008)$. In both cases, team production functions in the NBA were utilized to estimate the marginal product (and total product) of NBA employees in determining their level of productivity and used to evaluate the efficiency of decision-makers in the NBA. Additionally, Stewart, Mitchell \& Stavros (2007) have created a production function for Australian football based on Gerrard's sport team production model.

In the National Football League, several studies have attempted to estimate a production function using Gerrard's hierarchical structural model, most notably by Berri, Schmidt, and Brook (2006 \& 2007), with the formal details of the model provided in Berri (2007). Berri, Schmidt, and Brook (2006 \& 2007) and Berri (2007) model NFL production by estimating how teams acquire the ball, move the ball, maintain possession of the ball, and score for both teams' offense, and by looking at the corresponding variable for their opponent's scoring for the team's defense. Specifically, the offensive points scored model is a function of the team's opponent's kickoffs, opponent's punts, opponent's missed field goals, opponent's interceptions, opponent's fumbles lost, average starting position of drives, the team's yards gained, penalty yards and opponent's penalty yards, the number of plays the team runs, the team's third down conversion rate, the team's missed field goals, interceptions thrown, fumbles lost, the percentage of scores that are touchdowns and the extra point conversion rate. The defensive model is the same, except where the variable is measured using the opponent; this is changed to the exact same variable for their team and, when the variable is for the team, it is changed to the variable for their opponent. 
Finally, Coleman et. al. (2010) and Witte and Mirabile (2010) have found voter bias in the Associated Press College Football Poll. Although the Associated Press College Football Poll is no longer used in the calculation of the BCS average, this result does suggest that human judgment in evaluating NCAA football team performance may be biased. I will now turn to the estimation of a NCAA football production function.

\section{The NCAA FBS Complex Invasion Sport Production Model}

To estimate an NCAA football production, I collected on-field data ${ }^{1}$ on all NCAA FBS programs over the 2008 through 2017 seasons. In relation to the NFL model in Berri, Schmidt, and Brook (2007) and Berri (2007), the only variable that I do not have in the dataset is the average starting position of drives. Descriptive statistics for the variables employed in both the simple and complex invasion model are provided in Table 1a for the full (2008-2017) sample and in Table 1b for just the 2017 season.

The model used here follows Gerrard's (2007) complex invasion production model. The final stage of Gerrard's complex invasion sport production model relates team productivity (as measured by winning percent) as a function of team "offense" and "defense," as measured by points scored and points surrendered. Thus, I estimated the second stage of Gerrard's complex invasion sports production function for the NCAA football bowl subdivision over the 2008-2017 seasons. The second stage complex invasion sports production model is:

$$
\text { Winpct }_{\mathrm{i}}=\mathrm{f}\left(\text { Points }_{\mathrm{i}}, \text { Points }_{\mathrm{j}} \text {, SOS, Conference }\right)
$$

where team $\mathrm{i}=$ home team and $\mathrm{j}=$ the home team's opponent, and Winpct $_{\mathrm{i}}$ is the team i's winning percentage, Points is the total points scored by team $\mathrm{i}$ or team $\mathrm{j}$. Total points scored by team $\mathrm{i}$ is ex ante expected to be positively related to team i's winning percentage and total points scored by team $\mathrm{j}$ is ex ante expected to be negatively related to team i's winning percentage. Each team's strength of schedule (SOS) is also included, where SOS is calculated by taking the average of each opponent's rank played during the season using the complex invasion model. Additionally, athletic conference fixed effects are employed, controlling for any variation among different NCAA FBS conferences. The model is estimated using ordinary least squares with robust standard errors and the estimation results are presented in Table 2.

The model performs quite well, with an $\mathrm{R}^{2}=0.976$ over the 2008-2017 seasons. Both scoring independent variables - Points $_{\mathrm{i}}$ and Points $_{\mathrm{j}}$ - are of the correct theoretical sign and statistically significant at the $99 \%$ level of confidence. Likewise, all twelve conference ${ }^{2}$ fixed effects are statistically significant at the $99 \%$ confidence level. The only variable that is statistically insignificant is the measure of each team's strength of schedule. As such, I do not adjust for strength of schedule in the complex invasion college football production model below. Additionally, note that the estimated coefficients on Points $\mathrm{s}_{\mathrm{i}}$ and Points $\mathrm{s}_{\mathrm{j}}$ are equal in absolute value, which means that no adjustment is needed when calculating total team production in the complex invasion model below, indicating that "offense" and "defense" are statistically of equal importance in the determination of on-field team performance.

The drawback of focusing only on the second stage of the complex invasion sport production model is that it uses the final game results of Points $\mathrm{s}_{\mathrm{i}}$ and Points, $\mathrm{s}_{\mathrm{j}}$, as opposed to the actual on-field actions, such as yardage gained and turnovers to determine the impact of the final team productivity. To relate the activities on the field to team performance, Gerrard proposes a first stage of the complex invasion sport production model. The first stage model is presented next.

\section{Complex Invasion Sport Production Model for the NCAA Football Bowl Subdivision}

The first stage of the complex invasion sport production function is estimated by incorporating on-field variables that theoretically should affect team i's and team j's points scored and uses the marginal value of each of those statistically significant variables to calculate each NCAA FBS team's productivity. Using this methodology assumes that NCAA FBS teams that are more successful at completing actions that lead team i to score points and teams that are more successful at completing actions that prevent team $\mathrm{j}$ from scoring points are more productive teams. Thus, the actions and performance of players, and indirectly coaches, is used to measure each NCAA FBS team's productivity.

NCAA football games are a game between two different opponents. Hence only examining one of the two teams in the production function analysis would be akin to estimating a production function of a football scrimmage. Since that is not the objective, the complex invasion sports production model takes into account both how team $i$ and team $j$ impact team i's points scored and the points surrendered by team $i$ by their opponent, team $\mathrm{j}$. To that end two models are needed, one for team i's points scored and one for team $\mathrm{j}$ 's points surrendered against team i. The first stage of the complex invasion sports team i's points scored production function is modeled as:

$$
Y_{i}=f\left(\varphi_{i}, \gamma_{i, j}, \theta_{i}, \tau_{i}, \beta_{i}\right)
$$

\footnotetext{
${ }^{1}$ http://www.cbfstats.com

${ }^{2}$ Each of the three or four independent teams were coded as a conference. The independent schools are the twelfth conference.
} 
where $Y_{i}$ is team i's points scored against team $j$ and is a function of team $i$ acquiring the football from team $j\left(\varphi_{j}\right)$, the ability of team i in invading team j's territory $\left(\gamma_{i, j}\right)$, team i maintaining possession $\left(\theta_{i}\right)$, team i's scoring efficiency $\left(\tau_{i}\right)$, and controls for games played and conference affiliation of team $\dot{1}\left(\beta_{\mathrm{i}}\right)$.

Likewise for the first stage of the complex invasion sports team j's points scored production function is modeled as:

$$
Y_{j}=f\left(\varphi_{i}, \gamma_{i, j}, \theta_{j}, \tau_{j}, \beta_{i}\right)
$$

where $Y_{j}$ is team j's points scored against team i and is a function of team j acquiring the football from team $i\left(\varphi_{i}\right)$, the ability of team $j$ in invading team i's territory $\left(\gamma_{i, j}\right)$, team j's maintaining possession $\left(\theta_{j}\right)$, team j's scoring efficiency $\left(\tau_{j}\right)$, and controls for games played and conference affiliation $\left(\beta_{\mathrm{i}}\right)$. Both team i's points scored and team j's points scored production function models employ athletic conference fixed effects. Thus each model has 12 fixed effects as in the second stage complex invasion sport production model. Next I turn to the specific details in estimating both the Points ${ }_{\mathrm{i}}$ and Points $\mathrm{j}_{\mathrm{j}}$ models.

\section{Complex Invasion Sport Points Scored Production Function Estimation: 2008-2017}

The dependent variable in the points scored production function model is Points $\mathrm{s}_{\mathrm{i}}$ for NCAA football teams, covering the 2008-2017 seasons and only the 2017 season. Specifically, the points scored model is measured by the following variables: acquiring the ball (team j's kickoffs, team j's punts, team j's missed field goals, team j's interceptions, team j's fumbles lost, team j's failed fourth down conversions); invading team j's territory (team i's yards gained, team i's penalty yards and team j's penalty yards, the number of plays team i runs [rushing attempts, passing attempts, and sacks], team i's first down totals); maintaining possession (team i's missed field goals, team i's interceptions thrown, team i's fumbles lost, team i's failed fourth down conversions); scoring efficiency (team i's percentage of scores that are touchdowns and team i's extra point conversion rate); and game and conference adjustments (number of games played and an athletic conference fixed effect for team i's conference).

Notice that, other than not including team i's average starting position of drives, substituting team i's total first downs for team i's third down conversion rate, adding failed fourth down conversions by team $i$ and team $j$, and the number of games played (since each school does not play the same schedule like the NFL), the points scored model is identical to the Berri. et. al. $(2006,2007)$ NFL production model.

The model for Points for $_{\mathrm{i}}$ the 2008-2017 seasons is reported in Table 3a and for only the 2017 season is reported in Table $3 \mathrm{~b}$. Both models are estimated using ordinary least squares with robust standard errors and each model performs quite well, with an $\mathrm{R}^{2}$ equal to 0.995 (2008-2017) and an $\mathrm{R}^{2}$ equal to 0.997 (for just 2017), indicating that over $99 \%$ of the variation in the dependent variable is explained by the variation in the independent variables. Focusing on the full sample, each independent variable's sign is what was expected ${ }^{3}$ and statistically significant. For example, interpreting the regression results in Table 3a, each additional interception by team i's opponent (Interceptions $\mathrm{j}_{\mathrm{j}}$ ) yields on average an additional 3.262 points for team i. and each additional field goal attempt missed by team i (FieldGoalMissed ${ }_{j}$ ) results in an average decline in team i's points by 2.759 . The other variables are interpreted in the same manner. Thus, the model provides different weights for on-field actions that significantly affect the ability of team i to score points. Finally, each of the fixed effects for the offensive production function is negative and statistically significant.

Turning to Table 3b, a few variables are statistically insignificant (FieldGoalMissed ${ }_{\mathrm{j}}$, FourthDownMiss, PenaltyYards ${ }_{\mathrm{j}}$, FourthDownMiss ${ }_{i}$, PATPCT $_{i}$, and Games $_{i}$ ) and, as such, each variable is weighted as having zero effect on team i's points scored. The other variables are statistically significant, of the correct sign, and are used to calculate each teams total offensive production.

An example of the total offensive production calculation is presented in the appendix. For each variable that is statistically significant, the estimated weight multiplied by the number of times the variable occurred on the field during the season results in the total value for each variable. The coefficient (weight) for Kickoffs $\mathrm{s}_{\mathrm{j}}=1.837742$ and occurred 42 times during the 2017 season for Alabama, yielding a value of 77.185 . Summing up over all the significant variables yields each team's total offensive productivity. For the 2017 Alabama Crimson Tide, this results in a total of 405.220, which was the tenth best offense during the 2017 season.

\section{Complex Invasion Sport Points Surrendered Production Function Estimation: 2008-2017}

The estimation of Points ${ }_{j}$ by team $j$ is identical to team i's points scored model, except now the sides are reversed so the model is the same, except the subscripts are changed from $i$ to $j$ and $j$ to $i$.

Team j's production function results are reported in Table $4 \mathrm{a}$ for the full sample and in Table $4 \mathrm{~b}$ for only the 2017 season. Both models are estimated using ordinary least squares with robust standard errors and each model performs quite well, with an $\mathrm{R}^{2}$ of 0.995 for the full sample and an $\mathrm{R}^{2}$ of 0.997 for the 2017 season, and all the statistically significant variables having the correct sign. Focusing on the full sample, only team

\footnotetext{
${ }^{3}$ The sign on the number of plays is expected to be negative, since running a play is an opportunity cost to the team. For details, see Berri (2007).
} 
j's penalty yards were statistically insignificant and all the other on-field performance variables were statistically significant at the $95 \%$ level and are of the correct sign.

Similarly, the 2017 season model for Points $\mathrm{j}_{\mathrm{j}}$ reported in Table $4 \mathrm{~b}$ and the 2017 Points $_{\mathrm{i}}$ model have a few variables that are statistically

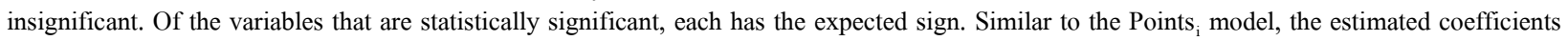
(weights) are used to calculate each team's overall defensive productivity in the same way as the offensive productivity was calculated in the Appendix.

\section{Most Productive NCAA Football Team in 2017: The University of Alabama Crimson Tide}

Given the results from the team i points scored and team $\mathrm{j}$ points surrendered models above, the last step is to apply how the complex invasion sports production model from equations (2) and (3) would rank NCAA FBS teams during the 2017 season. I used the estimated coefficients of the statistically significant variables (at the $95 \%$ confidence level) in each model to calculate team i's productivity in scoring points and team i's productivity in keeping team $\mathrm{j}$ from scoring points against team i. Once both calculations were made, I subtracted ${ }^{4}$ team i's productivity based on the estimated results from equation (3) against team i's estimated results from equation (2) to get team i's overall productivity and then ranked the total estimated results from highest to lowest.

NCAA football coaches and members of the media selected the University of Alabama as the national champion, given that they won the national championship game against the University of Georgia in January 2018. Using the complex invasion sports production model also leads to the conclusion that the University of Alabama was the most productive team in the Football Bowl Subdivision.

\section{NCAA FBS Complex Invasion Production Function Top 25 Teams (2008-2017)}

As a final application of the model, I report in Table 5 the top twenty-five teams in overall productivity during the last ten seasons. The calculations use the statistically significant coefficients (weights) from Table 3a for the "offensive productivity" and Table 4a for the "defensive productivity." Using the on-field statistics for all 1243 observations yields each team's offensive productivity and defensive productivity. Again, to calculate total productivity, I subtracted the defensive production from the offensive production and then ranked based on total productivity. As reported in Table 5, the Florida State University Seminoles were the best team, in terms of overall production during the 2008-2017 seasons, by a substantial amount. Looking at Table 5, we see that the University of Alabama is listed four times, Oregon three times, Florida State, Ohio State, and TCU twice.

Thus, the complex invasion FBS college football production model allows one to statistically compare teams that do not play each other in the same season, as well as compare teams' productivity in different seasons. This is one of the advantages of using this type of model when evaluating teams over time.

\section{Conclusions}

Each year pundits across the NCAA football landscape debate the validity of various NCAA football teams' relative worthiness to play for the national championship. Given this debate seems to revolve around which team is the best, in terms of production, I have created an NCAA football bowl subdivision production model to measure the performance of both the offense and defense and used the production model to create an end-of-season ranking of the top NCAA football bowl subdivision team for the 2017 season. The results indicate that the University of Alabama was the most productive team for the 2017 season.

Some of the strengths of the complex invasion sports production model are that the model estimates which on-field actions have a statistically significant impact on team i's scoring and team j's scoring and uses the marginal impact or value of each statistic to determine the overall NCAA FBS team productivity. Thus, the actions and performances of players (and indirectly coaches) is used to measure overall team productivity. Additionally, the marginal impact of team i and team j's actions that are statistically significant, in terms of points scored, are used to measure team production, not offensive and defensive points themselves; this avoids the incentive to run up the score to be more productive, which seems to be valued by NCAA football pundits. Thus, teams are more efficient on both team i's points scored (higher measure) and team i's points scored (lower measure), resulting in higher total productivity.

\footnotetext{
${ }^{4}$ The reason defensive productivity is subtracted follows from the negative sign on the coefficient on Points $\mathrm{j}_{\mathrm{j}}$ from the regression results in Table 2.
} 


\section{References}

Beard, T. Randolph, and Steven B. Caudill. 2009. "Who's number one? - ranking college football teams for the 2003 season." Applied Economics 41:307-310.

Berri, David J. 1999. "Who is 'Most Valuable'? Measuring the Player's Production of Wins in the National Basketball Association.” Managerial and Decision Economics 20:411-427.

Berri, David J. 2007. "Back to Back Evaluation on the Gridiron." In Statistical Thinking in Sport, edited by Jim Albert and Ruud Koning, 235-256. Chapman \& Hall/CRC.

Berri, David J. 2008. “A Simple Measure of Worker Productivity in the National Basketball Association.” In The Business of Sport, edited by Brad Humphreys \& Dennis Howard, 1-40. Westport, Conn.: Praeger.

Berri, David, Martin B. Schmidt, and Stacey L. Brook. 2006. The Wages of Wins: Taking Measure of the Many Myths in Modern Sports, Stanford, CA: Stanford Business Books.

Blass, Asher. 1992. "Does the Baseball Player's Market Contradict the Human Capital Model of Investment?" The Review of Economics and Statistics 74:261-268.

Coleman, B. Jay. 2005. "Minimizing Game Score Violations in College Football Rankings.” Interfaces 35: 483-497.

Coleman, B. Jay, Andres Gallo, Paul Mason, and Jeffrey W. Steagall. 2010. "Voter Bias in the Associated Press College Football Poll." Journal of Sports Economics 11:397-417.

Fair, Ray C. and John F. Oster. 2007. "College Football Rankings and Market Efficiency.” Journal of Sports Economics 8:3-18.

Gerrard, Bill. 2007. "Is the Moneyball Approach Transferable to Complex Invasion Team Sports?” International Journal of Sport Finance 2:214230.

Gill, Ryan, and Jerome Keating. 2009. “Assessing Methods for College Football Rankings.” Journal of Quantitative Analysis in Sports 5:Article 3. Accessed April 5, 2012. doi: 10.2202/1559-0410.1172.

Miles, William W., Gary T. Fowks, and Lisa O. Coulter. 2010. “AccuV College Football Ranking Model.” Journal of Quantitative Analysis in Sports 6:Article 10. Accessed April 5, 2012. doi:10.2202/1559-0410.1189.

Scully, Gerald. 1974. "Pay and Performance in Major League Baseball." The American Economic Review 64:915-930.

Stewart, Mark, Heather Mitchell and Constantino Starvos. 2007. "Moneyball Applied: Econometrics and the Identification and Recruitment of Elite Australian Football Players.” International Journal of Sport Finance 2:231-248.

West, Brady T. and Madhur Lamsal. 2008. "A New Application of Linear Modeling in the Prediction of College Football Bowl Outcomes and the Development of Team Ratings." Journal of Quantitative Analysis in Sports 4:Article 3. Accessed April 5, 2012. doi:10.2202/15590410.1115 .

Wigness, Maggie B., Chadd C. Williams, and Michael J. Rowell. 2010. “A New Iterative Method for Ranking College Football Teams.” Journal of Quantitative Analysis in Sports 6:Article 7. Accessed April 5, 2012. doi:10.2202/1559-0410.1242.

Witte, Mark D., and McDonald P. Mirabile. 2010. "Not So Fast, My Friend: Biases in College Football Polls.” Journal of Sports Economics 11:443455. 
NCAA Football Bowl Subdivision Production Function - Brook

Table 1a

Descriptive Statistics for NCAA FBS Simple and Complex Invasion Production Functions (Full Sample 2008-2017 seasons)

Variable

Mean

Std. Dev.

Min

Max

Dependent

Winpct

0.5183953

0.2217077

0

1

PointsI

$365.0024 \quad 105.7823$

117

723

PointsJ

341.7739

78.9128

106

572

Independent

FieldGoalMissedI

5.379726

2.329667

0

15

FieldGoalMissedJ

5.382944

2.357316

15

FirstDownTotalI

262.609

46.02712

424

FirstDownTotalJ

255.7265

32.65803

146

366

FourthDownMissI

9.502011

3.827894

23

FourthDownMissJ

9.705551

3.618283

26

FumblesI

9.625905

3.501903

24

FumblesJ

9.623492

3.432791

26

GamesI

12.68946

0.8532084

15

GamesJ

12.70877

0.6848807

15

InterceptionsI

11.65326

4.122281

29

Interceptions J

12.06114

4.640832

27

KickoffsI

70.73532

16.64061

128

KickoffsJ

67.23492

11.39961

102

PATPCTI

0.9364661

0.0552133

29

1.020408

PATPCTJ

0.9357779

0.0444329

0.7037037

1.026316

PenaltyYardsI

663.8817

147.7687

240

1273

PenaltyYardsJ

661.0483

121.8604

320

1218

PlaysI

917.4553

87.45088

687

1240 
8 EMERGING SPORT StUdies

Plays $J$

PuntsI

PuntsJ

SOS

TDScorePCTI

TDScorePCTJ

TotalYardsI

TotalYardsJ

Conference

ACC

Big10

Big12

BigEastAAC

CUSA

Ind

MidAmerican

MountainWest

Pac10Pac12

SEC

SunBelt

WAC

$\begin{array}{rr}913.8021 & 76.70395 \\ 62.2502 & 11.79335 \\ 65.13113 & 14.07021 \\ 65.65294 & 9.600766 \\ 0.7571242 & 0.07837 \\ 0.7468196 & 0.079081 \\ 5070.685 & 976.935 \\ 4911.057 & 683.5861\end{array}$

\subsection{7}

0.1005632

0.0852776

0.078037

0.1021722

0.0313757

0.1029767

0.084473

0.0917136

0.1061947

0.0788415

0.0337892
0.306142

0.3008705

0.2794067

0.2683378

0.3029965

0.1744011

0.3040507

0.2782079

0.2887374

0.3082106

0.2695997

0.1807589
Volume 1 (2018) 1205 97 113 94 $0.4705882 \quad 0.9491525$ $\begin{array}{ll}0.3902439 & 0.9459459\end{array}$ 2595 8387 $2387 \quad 7120$ 
NCAA Football Bowl Subdivision Production Function - Brook

Table 1b

Descriptive Statistics for NCAA FBS Simple and Complex Invasion Production Functions (2017 season)

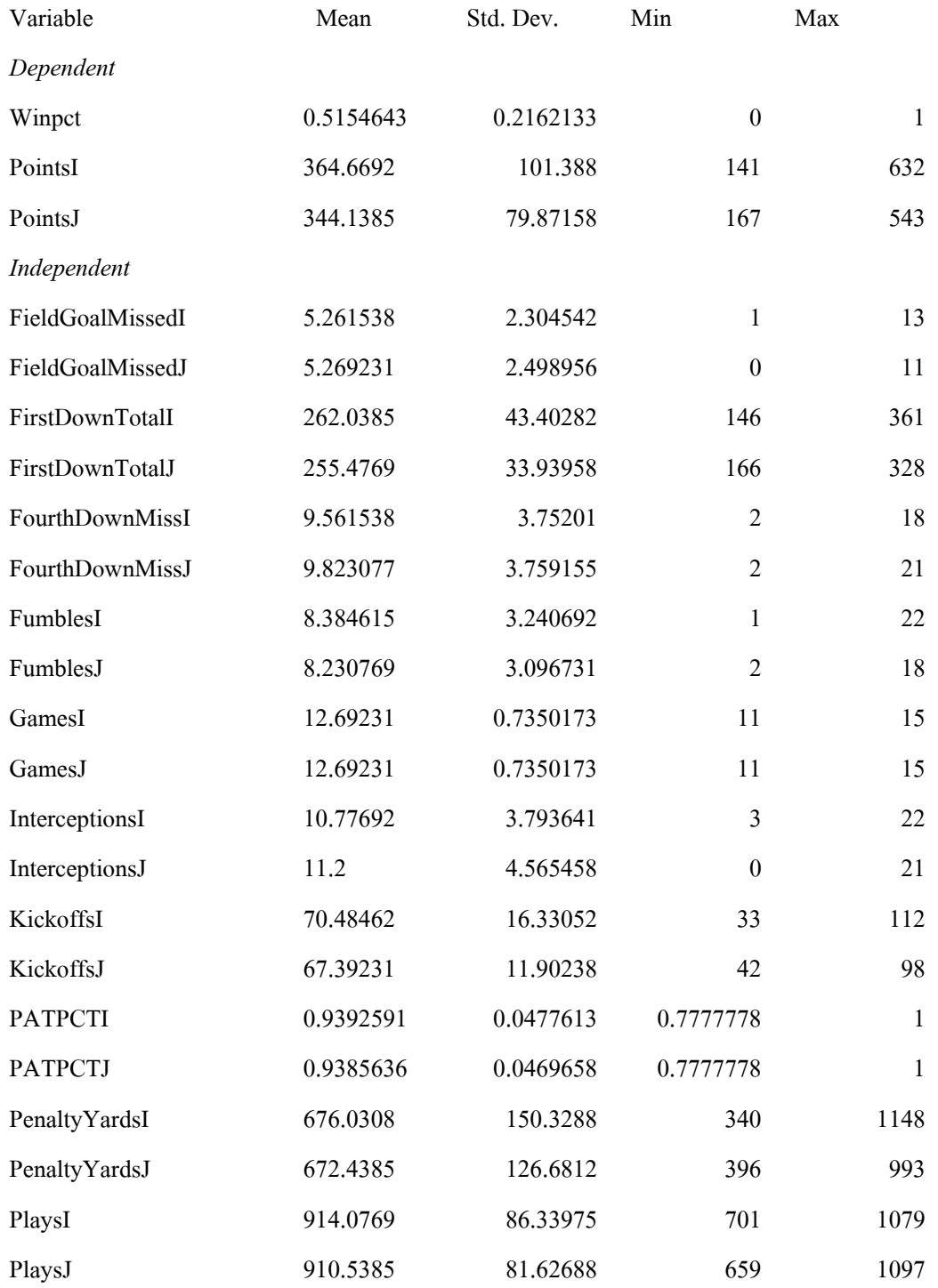


10 EMERGING SPORT StUdies

\begin{tabular}{|c|c|c|c|c|}
\hline PuntsI & 63.33077 & 11.54324 & 27 & 90 \\
\hline PuntsJ & 65.90769 & 15.00462 & 30 & 104 \\
\hline SOS & 68.04813 & 10.29098 & 47.66667 & 94 \\
\hline TDScorePCTI & 0.7606902 & 0.0771606 & 0.5833333 & 0.9491525 \\
\hline TDScorePCTJ & 0.7499394 & 0.0763719 & 0.5625 & 0.8955224 \\
\hline TotalYardsI & 5117 & 944.8186 & 2766 & 8114 \\
\hline TotalYardsJ & 4971 & 677.2443 & 3166 & 6500 \\
\hline \multicolumn{5}{|l|}{ Conference } \\
\hline $\mathrm{ACC}$ & 0.1076923 & 0.3111906 & 0 & 1 \\
\hline Big12 & 0.0769231 & 0.2675002 & 0 & 1 \\
\hline AAC & 0.0923077 & 0.2905796 & 0 & 1 \\
\hline Big10 & 0.1076923 & 0.3111906 & 0 & 1 \\
\hline CUSA & 0.1076923 & 0.3111906 & 0 & 1 \\
\hline IND & 0.0307692 & 0.1733599 & 0 & 1 \\
\hline MidAmerican & 0.0923077 & 0.2905796 & 0 & 1 \\
\hline MountainWest & 0.0923077 & 0.2905796 & 0 & 1 \\
\hline P12 & 0.0923077 & 0.2905796 & 0 & 1 \\
\hline SEC & 0.1076923 & 0.3111906 & 0 & 1 \\
\hline SunBelt & 0.0923077 & 0.2905796 & 0 & 1 \\
\hline
\end{tabular}

Volume 1 (2018) 
NCAA Football Bowl Subdivision Production Function - Brook

Table 2

NCAA FBS Simple Model (2008-2017) using robust standard errors

\begin{tabular}{|c|c|}
\hline & $\begin{array}{c}\text { Winpct } \\
\text { b/se }\end{array}$ \\
\hline \multirow[t]{2}{*}{ PointsI } & $0.001^{* * * *}$ \\
\hline & $(0.00)$ \\
\hline \multirow[t]{2}{*}{ PointsJ } & $-0.001^{* * *}$ \\
\hline & $(0.00)$ \\
\hline \multirow[t]{2}{*}{ SOS } & -0.000 \\
\hline & $(0.00)$ \\
\hline \multirow[t]{2}{*}{$\mathrm{ACC}$} & $0.441^{* * *}$ \\
\hline & $(0.03)$ \\
\hline \multirow[t]{2}{*}{ Big 12} & $0.433^{* * *}$ \\
\hline & $(0.03)$ \\
\hline \multirow[t]{2}{*}{ Big East/AAC } & $0.451^{* * *}$ \\
\hline & $(0.03)$ \\
\hline \multirow[t]{2}{*}{ Big 10} & $0.456^{* * *}$ \\
\hline & $(0.03)$ \\
\hline \multirow[t]{2}{*}{ CUSA } & $0.446^{* * *}$ \\
\hline & $(0.03)$ \\
\hline \multirow[t]{2}{*}{ Ind } & $0.441^{* * *}$ \\
\hline & $(0.03)$ \\
\hline \multirow[t]{2}{*}{ Mid American } & $0.448^{* * *}$ \\
\hline & $(0.03)$ \\
\hline \multirow[t]{2}{*}{ Mountain West } & $0.454^{* * *}$ \\
\hline & $(0.03)$ \\
\hline Pac 10/Pac 12 & $0.440^{* * *}$ \\
\hline
\end{tabular}


12 EMERGING SPORT StUdies

\begin{tabular}{lc} 
SEC & $(0.03)$ \\
& $0.445^{* * *}$ \\
Sun Belt & $(0.02)$ \\
& $0.453^{* * *}$ \\
WAC & $(0.03)$ \\
& $0.459^{* * *}$ \\
$\mathrm{R}^{2}=$ & $(0.03)$ \\
$\mathrm{N}=$ & 0.976 \\
\hline${ }^{*} p<0.05, \quad p<0.01, \quad p<0.001$ & 1243 \\
\hline
\end{tabular}


NCAA Football Bowl Subdivision Production Function - Brook

Table 3a

NCAA FBS Complex Invasion Offense Model (2008-2017) using robust standard errors

\begin{tabular}{|c|c|}
\hline & $\begin{array}{c}\text { PointsI } \\
\text { b/se }\end{array}$ \\
\hline \multirow[t]{2}{*}{ Kickoffs J } & $1.148^{* * *}$ \\
\hline & $(0.14)$ \\
\hline \multirow[t]{2}{*}{ PuntsJ } & $1.430^{* * *}$ \\
\hline & $(0.12)$ \\
\hline \multirow[t]{2}{*}{ FieldGoalMissedJ } & $1.041^{* *}$ \\
\hline & $(0.35)$ \\
\hline \multirow[t]{2}{*}{ InterceptionsJ } & $3.262^{* * *}$ \\
\hline & $(0.21)$ \\
\hline \multirow[t]{2}{*}{ FumblesJ } & $3.535^{* * *}$ \\
\hline & $(0.24)$ \\
\hline \multirow[t]{2}{*}{ FourthDownMissJ } & $1.727^{* * *}$ \\
\hline & $(0.24)$ \\
\hline \multirow[t]{2}{*}{ TotalYardsI } & $0.062^{* * *}$ \\
\hline & $(0.00)$ \\
\hline \multirow[t]{2}{*}{ PenaltyYardsI } & $-0.026^{* * *}$ \\
\hline & $(0.01)$ \\
\hline \multirow[t]{2}{*}{ PenaltyYardsJ } & $0.020^{* *}$ \\
\hline & $(0.01)$ \\
\hline \multirow[t]{2}{*}{ PlaysI } & $-0.362^{* * *}$ \\
\hline & $(0.03)$ \\
\hline \multirow[t]{2}{*}{ FirstDownTotalI } & $0.823^{* * *}$ \\
\hline & $(0.09)$ \\
\hline FieldGoalMissedI & $-2.759^{* * *}$ \\
\hline
\end{tabular}




$$
\text { (0.33) }
$$

InterceptionsI

$-2.573^{* * *}$

(0.21)

FumblesI

$-1.777^{* * *}$

(0.22)

FourthDownMissI

$-2.226^{* * *}$

(0.25)

TDScorePCTI

$129.461^{* * *}$

(11.44)

PATPCTI

$61.783^{* *}$

(20.46)

GamesI

$4.490^{* * * *}$

(1.36)

ACC

$-225.016^{* * *}$

(25.53)

Big 12

$-222.186^{* * * *}$

(25.59)

Big East/AAC

$-226.127^{* * * *}$

(25.35)

Big 10

$-226.005^{* * * *}$

(25.46)

CUSA

$-224.882^{* * * *}$

(25.50)

Ind

$-234.659^{* * *}$

(25.67)

Mid American

$-234.264^{* * *}$

(25.06)

Mountain West

$-230.334^{* * *}$

(25.52) 
NCAA Football Bowl Subdivision Production Function - Brook

Pac 10/Pac 12 $-222.833^{* * *}$

(25.49)

SEC

$-226.403^{* * *}$

(25.41)

Sun Belt

$-228.759^{* * *}$

(25.07)

WAC

$-232.069^{* * *}$

(25.84)

\begin{tabular}{ll}
\hline $\mathrm{R}^{2}=$ & 0.995 \\
$\mathrm{~N}=$ & 1243
\end{tabular}

${ }^{*} p<0.05,{ }^{* *} p<0.01, \quad{ }^{* * *} p<0.001$ 
16 EMERGING SPORT STUdies

Table $3 b$

NCAA FBS Complex Invasion Points Scored Model (2017) using robust standard errors

\begin{tabular}{|c|c|}
\hline & $\begin{array}{c}\text { PointsI } \\
\text { b/se }\end{array}$ \\
\hline Kickoffs J & $\begin{array}{c}1.838^{* * * *} \\
(0.38)\end{array}$ \\
\hline Punts $J$ & $\begin{array}{c}1.985^{* * * *} \\
(0.34)\end{array}$ \\
\hline FieldGoalMissedJ & $\begin{array}{l}1.255 \\
(1.02)\end{array}$ \\
\hline Interceptions $J$ & $\begin{array}{c}3.231^{* * * *} \\
(0.60)\end{array}$ \\
\hline FumblesJ & $\begin{array}{c}4.305^{* * * *} \\
(0.76)\end{array}$ \\
\hline FourthDownMissJ & $\begin{array}{l}1.173 \\
(0.76)\end{array}$ \\
\hline TotalYardsI & $\begin{array}{c}0.060^{* * *} \\
(0.01)\end{array}$ \\
\hline PenaltyYardsI & $\begin{array}{c}-0.060^{* * *} \\
(0.02)\end{array}$ \\
\hline PenaltyYardsJ & $\begin{array}{l}-0.003 \\
(0.02)\end{array}$ \\
\hline PlaysI & $\begin{array}{c}-0.444^{* * *} \\
(0.08)\end{array}$ \\
\hline FirstDownTotalI & $\begin{array}{c}1.045^{* * * *} \\
(0.26)\end{array}$ \\
\hline FieldGoalMissedI & $\begin{array}{c}-3.131^{* *} \\
(0.94)\end{array}$ \\
\hline
\end{tabular}


NCAA Football Bowl Subdivision Production Function - Brook

\begin{tabular}{|c|c|}
\hline InterceptionsI & $-3.520^{* * *}$ \\
\hline & $(0.68)$ \\
\hline FumblesI & $-2.059^{* *}$ \\
\hline & $(0.78)$ \\
\hline FourthDownMissI & -1.306 \\
\hline & $(0.73)$ \\
\hline TDScorePCTI & $110.274^{* * *}$ \\
\hline & (28.09) \\
\hline PATPCTI & 78.360 \\
\hline & (51.99) \\
\hline GamesI & 1.736 \\
\hline & $(4.80)$ \\
\hline $\mathrm{ACC}$ & $-212.917^{* *}$ \\
\hline & $(68.66)$ \\
\hline Big12 & $-201.096^{* *}$ \\
\hline & $(68.20)$ \\
\hline AAC & $-192.829^{* *}$ \\
\hline & $(67.28)$ \\
\hline Big10 & $-199.075^{* *}$ \\
\hline & (68.89) \\
\hline CUSA & $-207.187^{* *}$ \\
\hline & (66.89) \\
\hline IND & $-203.899^{* *}$ \\
\hline & $(68.39)$ \\
\hline MidAmerican & $-201.281^{* *}$ \\
\hline & $(66.81)$ \\
\hline MountainWest & $-217.701^{* *}$ \\
\hline & $(67.83)$ \\
\hline $\mathrm{P} 12$ & $-190.199^{* *}$ \\
\hline
\end{tabular}




\section{(68.41)}

SEC

$-203.009^{* *}$

(68.55)

SunBelt

$-210.685^{* *}$

(66.70)

\begin{tabular}{lc}
\hline $\mathrm{R}^{2}=$ & 0.997 \\
$\mathrm{~N}=$ & 130 \\
\hline
\end{tabular}

${ }^{*} p<0.05,{ }^{* *} p<0.01,{ }^{* * *} p<0.001$ 
NCAA Football Bowl Subdivision Production Function - Brook

Table 4a

NCAA FBS Complex Invasion Points Surrendered Model (2008-2017) using robust standard errors

\begin{tabular}{|c|c|}
\hline & $\begin{array}{c}\text { PointsJ } \\
\text { b/se }\end{array}$ \\
\hline \multirow[t]{2}{*}{ KickoffsI } & $1.347^{* * *}$ \\
\hline & $(0.14)$ \\
\hline \multirow[t]{2}{*}{ PuntsI } & $1.579^{* * * *}$ \\
\hline & $(0.12)$ \\
\hline \multirow[t]{2}{*}{ FieldGoalMissedI } & $0.946^{* *}$ \\
\hline & $(0.35)$ \\
\hline \multirow[t]{2}{*}{ InterceptionsI } & $3.180^{* * *}$ \\
\hline & $(0.19)$ \\
\hline \multirow[t]{2}{*}{ FumblesI } & $3.331^{* * *}$ \\
\hline & $(0.22)$ \\
\hline \multirow[t]{2}{*}{ FourthDownMissI } & $2.076^{* * *}$ \\
\hline & $(0.23)$ \\
\hline \multirow[t]{2}{*}{ TotalYardsJ } & $0.064^{* * *}$ \\
\hline & $(0.00)$ \\
\hline \multirow[t]{2}{*}{ PenaltyYardsI } & $0.011^{*}$ \\
\hline & $(0.01)$ \\
\hline \multirow[t]{2}{*}{ PenaltyYardsJ } & -0.013 \\
\hline & $(0.01)$ \\
\hline \multirow[t]{2}{*}{ PlaysJ } & $-0.439^{* * *}$ \\
\hline & $(0.03)$ \\
\hline \multirow[t]{2}{*}{ FirstDownTotalJ } & $0.878^{* * *}$ \\
\hline & $(0.09)$ \\
\hline \multirow[t]{2}{*}{ FieldGoalMissedJ } & $-2.433^{* * *}$ \\
\hline & $(0.31)$ \\
\hline
\end{tabular}


20 Emerging SPORT StUdies

InterceptionsJ

$-2.147^{* * *}$

(0.19)

FumblesJ

$-1.962^{* * *}$

$(0.23)$

FourthDownMissJ

$-1.597^{* * *}$

$(0.24)$

TDScorePCTJ

$132.689^{* * *}$

(10.83)

PATPCTJ

$51.206^{* *}$

(16.48)

GamesJ

$-4.173^{*}$

(1.76)

ACC

$-101.655^{* * * *}$

(24.84)

Big 12

$-101.218^{* * * *}$

(24.60)

Big East/AAC

$-101.922^{* * * *}$

(24.80)

Big 10

$-101.658^{* * *}$

(24.87)

CUSA

$-95.036^{* * * *}$

(24.86)

Ind

$-107.967^{* * * *}$

(24.94)

Mid American

$-104.126^{* * *}$

(24.82)

Mountain West

$-99.086^{* * *}$

(24.97)

Pac 10/Pac 12

$-98.570^{* * *}$ 
NCAA Football Bowl Subdivision Production Function - Brook

$$
\text { (24.78) }
$$

SEC

Sun Belt

$-105.384^{* * *}$

(24.92)

$-97.158^{* * *}$

(24.54)

WAC

$-96.792^{* * *}$

(25.09)

\begin{tabular}{lr}
\hline $\mathrm{R}^{2}=$ & 0.995 \\
$\mathrm{~N}=$ & 1243
\end{tabular}

${ }^{*} p<0.05, \quad p<0.01, \quad p<0.001$ 
22 EMERGING SPORT StUdies

Volume 1 (2018)

Table $4 \mathrm{~b}$

NCAA FBS Complex Invasion Points Surrendered Model (2017) using robust standard errors

\begin{tabular}{|c|c|}
\hline & $\begin{array}{c}\text { PointsJ } \\
\text { b/se }\end{array}$ \\
\hline \multirow[t]{2}{*}{ KickoffsI } & $1.661^{* * * *}$ \\
\hline & $(0.38)$ \\
\hline \multirow[t]{2}{*}{ PuntsI } & $1.775^{* * *}$ \\
\hline & $(0.39)$ \\
\hline \multirow[t]{2}{*}{ FieldGoalMissedI } & 1.098 \\
\hline & (1.13) \\
\hline \multirow[t]{2}{*}{ InterceptionsI } & $3.376^{* * *}$ \\
\hline & $(0.75)$ \\
\hline \multirow[t]{2}{*}{ FumblesI } & $4.117^{* * * *}$ \\
\hline & $(0.69)$ \\
\hline \multirow[t]{2}{*}{ FourthDownMissI } & 0.989 \\
\hline & $(0.74)$ \\
\hline \multirow[t]{2}{*}{ TotalYardsJ } & $0.060^{* * *}$ \\
\hline & $(0.01)$ \\
\hline \multirow[t]{2}{*}{ PenaltyYardsI } & 0.021 \\
\hline & $(0.02)$ \\
\hline \multirow[t]{2}{*}{ PenaltyYardsJ } & -0.046 \\
\hline & $(0.02)$ \\
\hline \multirow[t]{2}{*}{ PlaysJ } & $-0.359^{* * *}$ \\
\hline & $(0.09)$ \\
\hline \multirow[t]{2}{*}{ FirstDownTotalJ } & $0.960^{* *}$ \\
\hline & $(0.30)$ \\
\hline \multirow[t]{2}{*}{ FieldGoalMissedJ } & $-3.680^{* * *}$ \\
\hline & $(0.97)$ \\
\hline
\end{tabular}




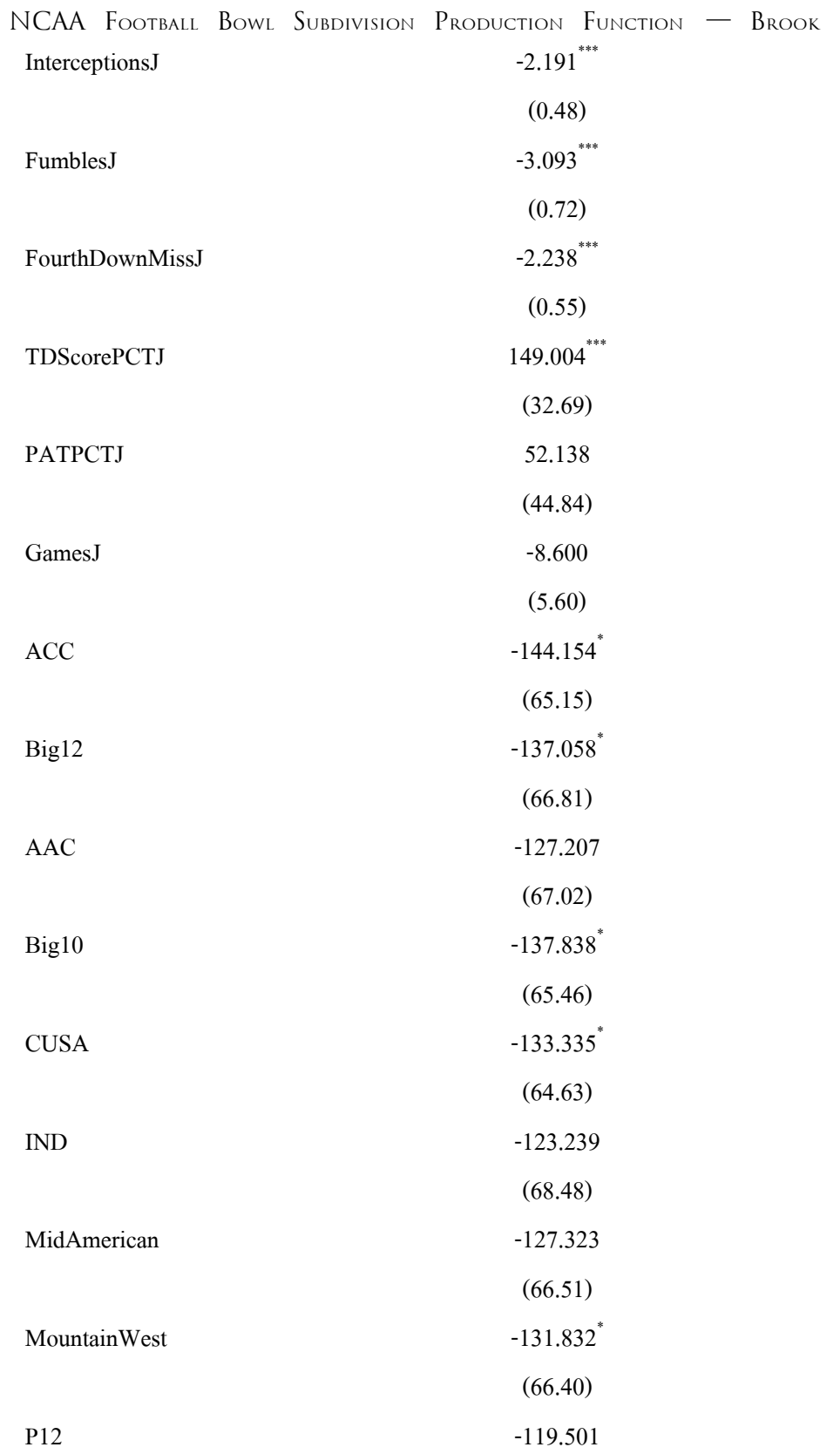


(67.58)

SEC

$-125.959$

(65.70)

SunBelt

$-131.774^{*}$

(64.21)

\begin{tabular}{lc}
\hline $\mathrm{R}^{2}=$ & 0.997 \\
$\mathrm{~N}=$ & 130 \\
\hline
\end{tabular}

${ }^{*} p<0.05,{ }^{* *} p<0.01,{ }^{* * *} p<0.001$ 
NCAA Football Bowl Subdivision Production Function - Brook

Table 5

NCAA FBS Complex Invasion Production Function Top 25 Productive Teams (2008-2017)

\begin{tabular}{|c|c|c|c|c|c|}
\hline$\underline{\text { Rank }}$ & Name & $\underline{\text { Season }}$ & Off Prod & Def Prod & Total Prod \\
\hline 1 & Florida State & 2013 & 896.716 & 306.561 & 590.155 \\
\hline 2 & Alabama & 2016 & 787.336 & 286.647 & 500.689 \\
\hline 3 & Boise State & 2010 & 783.461 & 283.395 & 500.066 \\
\hline 4 & Houston & 2011 & 934.610 & 436.822 & 497.788 \\
\hline 5 & Alabama & 2017 & 744.183 & 260.344 & 483.838 \\
\hline 6 & Alabama & 2012 & 769.334 & 287.080 & 482.255 \\
\hline 7 & Baylor & 2013 & 885.711 & 405.910 & 479.801 \\
\hline 8 & TCU & 2010 & 765.440 & 286.717 & 478.722 \\
\hline 9 & Alabama & 2011 & 658.058 & 181.742 & 476.315 \\
\hline 10 & Washington & 2016 & 806.695 & 335.786 & 470.909 \\
\hline 11 & Oregon & 2014 & 927.276 & 462.488 & 464.789 \\
\hline 12 & Florida & 2009 & 726.106 & 263.398 & 462.708 \\
\hline 13 & Louisville & 2013 & 712.094 & 250.037 & 462.058 \\
\hline 14 & TCU & 2014 & 814.460 & 361.308 & 453.152 \\
\hline 15 & Oregon & 2013 & 826.068 & 374.790 & 451.278 \\
\hline 16 & LSU & 2011 & 691.964 & 241.000 & 450.964 \\
\hline 17 & Florida State & 2012 & 758.359 & 309.432 & 448.926 \\
\hline 18 & Oregon & 2010 & 811.577 & 363.182 & 448.395 \\
\hline 19 & Wisconsin & 2011 & 815.416 & 367.817 & 447.600 \\
\hline 20 & $\mathrm{TCU}$ & 2009 & 737.193 & 294.984 & 442.209 \\
\hline 21 & Ohio State & 2017 & 806.813 & 364.773 & 442.040 \\
\hline 22 & Ohio State & 2010 & 715.986 & 274.317 & 441.668 \\
\hline 23 & Marshall & 2014 & 857.377 & 428.184 & 429.193 \\
\hline 24 & Clemson & 2016 & 834.284 & 407.230 & 427.054 \\
\hline 25 & Oregon & 2012 & 824.026 & 398.524 & 425.502 \\
\hline
\end{tabular}


Appendix

University of Alabama 2017 Points Scored Example

\begin{tabular}{|c|c|c|c|c|}
\hline Variable & Weight & Significant? & Alabama & Value \\
\hline Kickoffs J & 1.837742 & 1 & 42 & 77.185 \\
\hline PuntsJ & 1.984604 & 1 & 94 & 186.553 \\
\hline FieldGoalMissedJ & 1.254589 & 0 & 2 & 0.000 \\
\hline Interceptions $J$ & 3.231345 & 1 & 19 & 61.396 \\
\hline FumblesJ & 4.304917 & 1 & 5 & 21.525 \\
\hline FourthDownMissJ & 1.17264 & 0 & 12 & 0.000 \\
\hline TotalYardsI & 0.059507 & 1 & 6217 & 369.956 \\
\hline PenaltyYardsI & -0.06031 & 1 & 569 & -34.316 \\
\hline PenaltyYardsJ & -0.00309 & 0 & 455 & 0.000 \\
\hline PlaysI & -0.44449 & 1 & 971 & -431.603 \\
\hline FirstDownTotalI & 1.045193 & 1 & 311 & 325.055 \\
\hline FieldGoalMissedI & -3.13073 & 1 & 9 & -28.177 \\
\hline InterceptionsI & -3.51957 & 1 & 3 & -10.559 \\
\hline FumblesI & -2.05861 & 1 & 7 & -14.410 \\
\hline FourthDownMissI & -1.30582 & 0 & 3 & 0.000 \\
\hline TDScorePCTI & 110.2743 & 1 & 0.776471 & 85.625 \\
\hline PATPCTI & 78.36048 & 0 & 0.984848 & 0.000 \\
\hline GamesI & 1.735894 & 0 & 14 & 0.000 \\
\hline ACC & -212.917 & 1 & 0 & 0.000 \\
\hline Big12 & -201.096 & 1 & 0 & 0.000 \\
\hline AAC & -192.829 & 1 & 0 & 0.000 \\
\hline Big10 & -199.075 & 1 & 0 & 0.000 \\
\hline CUSA & -207.187 & 1 & 0 & 0.000 \\
\hline IND & -203.899 & 1 & 0 & 0.000 \\
\hline MidAmerican & -201.281 & 1 & 0 & 0.000 \\
\hline
\end{tabular}


NCAA Football Bowl Subdivision Production Function - Brook

MountainWest

P12

SEC

SunBelt

Total $=$
$-217.701$

$-190.199$

$-203.009$

$-210.685$

1

1

1

1
0

0

0.000

0.000

1

0

$-203.009$

0.000

405.220 